\title{
ASSÉDIO MORAL NAS ORGANIZAÇÕES: IMPACTOS E O PAPEL DOS PROFISSIONAIS DE RECURSOS HUMANOS
}

\section{BULLYING IN ORGANIZATIONS: IMPACTS AND THE ROLE OF HUMAN RESOURCES PROFESSIONALS}

\author{
Cacilda N. Lorentz ${ }^{*}$ \\ Luiz Claúdio de Lima* \\ Antônio Del Maestro Filho ${ }^{* * *}$
}

\begin{abstract}
RESUMO
Este ensaio teórico objetiva promover reflexões sobre o assédio moral nas organizações e discutir a posição dos profissionais de Recursos Humanos. Busca compreender o assédio moral conceitualmente, contextualizado no sistema macro socioeconômico, além de analisá-lo à luz dos processos de Recursos Humanos. Subliminarmente, ressalta a importância estratégica da área de Recursos Humanos nas organizações, e também apresenta críticas sobre as práticas de gestão quando se mostram inadequadas. Entre as conclusões, destaca-se que o assédio moral no trabalho tem causas múltiplas, caracterizando-se como um problema grave que requer soluções integradas. Os profissionais de $\mathrm{RH}$ ainda se envolvem pouco nestas questões e precisam de melhor capacitação para lidar adequadamente com o assédio moral. Este quesito é preponderante para o sucesso das pessoas e das equipes de trabalho, na medida em que se nota uma premência no resgate de valores éticos e no estabelecimento de relacionamentos interpessoais baseados no respeito pelo ser humano.
\end{abstract}

Palavras- chaves: Assédio moral, violência no trabalho, recursos humanos.

\begin{abstract}
This essay aims to promote reflections on moral harassment in organizations and discuss the position of human resource professionals. It seeks to understand moral harassment conceptually, contextualised in macro socio-economic system, as well as analyze it in the light of the process of Human Resources. The essay emphasizes the strategic importance of Human Resources in organizations, in addition to criticizing management practices when they prove inadequate. Among the conclusions, it is emphasized that moral harassment in the workplace has multiple causes, characterized as a serious problem that requires integrated solutions. HR professionals still get little involved in these issues and need better training to adequately deal with moral harassment. This question is vital for the success of individuals and of work teams, as it is observed an urge to rescue ethical values and to establish interpersonal relationships based on respect for human beings.
\end{abstract}

Keywords: Moral harassment, violence at the workplace, human resources.

\footnotetext{
“Doutora em Administração pela UFMG, mestre em administração, psicóloga. Professora da Universidade FUMEC e consultora organizacional na área de gestão de pessoas.

"* Professor do IBMEC / Belo Horizonte, doutor em Administração pela Universidade FUMEC, mestre em engenharia de produção pela UFSC, administrador e consultor em gestão de pessoas

*** Doutor em Administração pela Universidade Federal de Minas Gerais. Atualmente é professor adjunto do Departamento de Ciências Administrativas da FACE/UFMG.
} 


\section{Introdução}

Discutir questões relativas ao assédio moral mostra-se relevante e necessário, principalmente por se tratar de tema pouco explorado em estudos acadêmicos e ainda considerado recente, pois este fenômeno só foi identificado e denominado com esta nomenclatura no final da década de 1990, tendo-se popularizado com a publicação em 1998 do livro " $L e$ Harcèlement moral: la violence pervese au quotidien” de Marie-France Hirigoyen. A partir daí, nota-se um crescente número de artigos e pesquisas sobre este tema (BARRETO, 2000, 2005; HIRIGOYEN, 2002; HELOANI 2003, 2004; NASCIMENTO, 2007; FREITAS, HELOANI, BARRETO, 2008), oriundos da diversidade de abordagens existentes, que não apresentam consenso em seus aspectos conceituais, determinantes, de intervenções ou mesmo no que se refere à busca de soluções. Trata-se, portanto, de um tema multidisciplinar que demanda diferentes olhares, sejam de cunho psicológico, sociológico, médico, jurídico, e administrativo (com foco na gestão), pois é nas organizações que este fenômeno se faz presente de forma mais frequente, podendo assim, ser considerado um tipo de violência urbana. Estes diversos enfoques revelam a complementaridade necessária para uma ampla compreensão do assédio moral no contexto de trabalho.

Contudo, o esclarecimento e a maior conscientização sobre o assédio moral e suas consequências vêm gradativamente alcançando diversos segmentos da sociedade, em especial os empregados, gestores, sindicatos e juristas, que passaram a tratar o tema com atenção e preocupação. Nota-se, também, que em vários países a legislação sobre o assunto avançou, inclusive no Brasil, que apesar de ainda ser incipiente, pode-se dizer que nos últimos anos obteve significativas conquistas (PELI; TEIXEIRA, 2006). A despeito ou por conta destes progressos observa-se também o crescimento no número de denúncias de tais práticas.

Diante deste contexto, podem-se efetuar alguns questionamentos: $\mathrm{O}$ que fazer para banir as práticas de assédio moral do contexto de trabalho? Por que a área de Recursos Humanos (RH), que deveria prevenir e intervir em problemas deste tipo, ainda é pouco citada nos artigos e pesquisas acadêmicas, e quando aparecem são consideradas omissas, coni- ventes ou negligentes? Qual o posicionamento esperado e desejado dos profissionais de $\mathrm{RH}$ para lidar com este problema?

Este ensaio teórico pretende apresentar e analisar o assédio moral nas organizações de trabalho, a partir de uma revisão bibliográfica e, especificamente, visa compreender este fenômeno na perspectiva da gestão de Recursos Humanos.

Além desta introdução, este trabalho está estruturado de forma a abranger os seguintes aspectos: 1- Compreensão conceitual do assédio moral em distintas abordagens; 2 - discussão das questões referentes ao contexto de trabalho e sua relação com o assédio moral; 3 - contextualização da gestão de Recursos Humanos, seu papel, práticas e inadequações; 4 - diferenciação do assédio moral de outras práticas; e, finalmente, apresenta algumas reflexões e recomendações finais.

\section{Compreendendo o assédio moral}

Não há uma definição precisa e consensual sobre o tema assédio moral. Também conhecido como violência moral, mobbing, bullying, acoso moral, psicoterrorismo ou terror psicológico no trabalho, o assédio moral é interpretado sob as óticas de abordagens distintas, o que ocasiona múltiplas compreensões desse fenômeno. Além disto, a escassez de conhecimento e a pouca clareza conceitual faz com que o termo venha a ser utilizado inadequadamente com certa frequência, seja para designar outros processos relativos a inadequações de cunho relacionais ou atitudinais, ou de forma banalizada para se referir a questões corriqueiras. Cabe ainda ressaltar que, além das divergências conceituais sobre o tema, notam-se questionamentos e posições contraditórias sobre a validação e adequação das metodologias empregadas nas pesquisas e seus métodos e instrumentos aplicados para coleta de dados. Portanto, pode-se dizer que se trata de tema amplo, complexo e que merece aprofundamento de estudos (DI MARTINO; HOEL; COOPER, 2003; MACIEL et al, 2007; SINA, 2007, FIORELLI; FIORELLI; MALHADAS, 2007; GUEDES, 2008, NASCIMENTO, 2009, GLINA; SOBOLL, 2012).

Heinz Leymann foi um dos percussores a escrever sobre o tema em 1989, mas foi Marie-France 
Hirigoyen, em 1998, que atraiu maior atenção sobre as questões do assédio moral ao difundir e impulsionar novos estudos. Segundo Soares (2012, p. 285) o livro dessa autora representou "uma importância política muito grande, pois catalisou um movimento social determinante em torno dessa forma de violência no trabalho".

Hirigoyen (2008) afirma que casos de violência moral acontecem em situações cotidianas, sendo comum tanto no contexto familiar, como, por exemplo, nos relacionamento entre casais e também no contexto organizacional ou empresarial. Destaca que o assédio moral está relacionado à violência direta e indireta e trata-se de um movimento perverso, no qual um indivíduo, na sua busca constante por poder e autoestima desconsidera ao outro sua condição humana. Assim, o perverso tenta utilizar, descartar e destruir o outro, para atingir seus objetivos pessoais e não demonstra nenhum sentimento de culpa. Nas empresas, o assédio moral é definido como "toda e qualquer conduta abusiva manifestando-se, sobretudo, por comportamento, palavras, atos, gestos, escritos que possam trazer dano à personalidade, à dignidade ou à integridade física ou psíquica de uma pessoa, pôr em perigo seu emprego ou degradar o ambiente de trabalho" (HIRIGOYEN, 2008, p. 65)

Ao estudar o assédio moral nos países da união europeia, Di Martino, Hoel e Cooper (2003) ressaltam o desafio da conceituação e delimitação deste fenômeno, pois sob a rubrica da violência no trabalho encontram-se diversos comportamentos, e a percepção do que é considerado aceitável ou não, depende da cultura e do contexto em que está inserido.

O assédio moral é associado por Guedes (2008) a um conjunto de práticas de violência psicológica que visam o isolamento, o prejuízo da reputação e a depreciação do trabalho da vítima, atingindo de forma reiterada várias esferas da sua vida.

Heloani (2004) ressalta que o assédio moral é caracterizado pela intencionalidade deliberada e constante de desqualificação do outro, o que acarreta sua fragilização. Freitas (2007, p. 2) também destaca a intencionalidade do assédio moral, o qual identifica como:

uma conduta abusiva, intencional, frequente e repetida que visa, além de diminuir, humilhar, vexar, constranger, desqualificar e demolir psicologicamente um indivíduo ou grupo, degradando suas condições de trabalho, chegando mesmo a atingir sua dignidade, além de comprometer sua integridade pessoal e profissional.

Apesar de a intencionalidade aparecer frequentemente como um fator de evidência da existência do assédio, este tópico também não é consenso entre os estudiosos do tema. Para Fiorelli, Fiorelli e Malhadas (2007) e Soares e Oliveira (2012, p.196) "as definições de assédio moral não incluem a intencionalidade, pois o assediador nem sempre tem a intenção de assediar, mas, com ou sem intenção, essa violência pode existir e causar dano". Citando estudos de Hoel, Rayner e Cooper (1999) e Verdasca (2010) esses autores ressaltam a dificuldade de encontrar dados reais de que a intencionalidade exista, e afirmam que quando é percebido por parte do assediado (real ou não), configura-se o assédio.

Uma abordagem mais ampla compreende a questão do assédio moral inserido no contexto macroeconômico e social (DI MARTINO; HOEL; COOPER, 2003; HELOANI, 2004, 2011). Nesta perspectiva, Heloani (2004) percebe o indivíduo como resultado de uma construção sócio-histórica, portanto, produtor e ao mesmo tempo sujeito das inter-relações que estabelece na sociedade e suas respectivas relações de poder. Ressalta que a atual economia neoliberal e seu modelo econômico favorecem o surgimento desta forma de violência, que vem crescendo nos últimos anos (HELOANI, 2011).

Em uma concepção jurídica, Sina (2007, p. 18) considera que "o assédio moral pode ser considerado um abuso emocional, com finalidade de afastar o empregado das relações profissionais, por meio de boatos, intimidações, humilhações, descrédito e isolamento". As formas como pode acontecer são distintas, desde ações que humilham e degradam abertamente, até ações mais dissimuladas, surgindo e configurando de maneira subliminar, tais como boatos ou comentários disseminados nos corredores da organização.

Também na perspectiva jurídica, Nascimento (2009) destaca que no assédio moral há ofensa à honra e à dignidade do trabalhador, e a sua conduta abusiva se configura como sendo

de natureza psicológica, que atenta contra a dignidade psíquica do indivíduo, de forma reiterada, possui quatro elementos, a saber: a) 
Conduta abusiva; b) Natureza psicológica do atentado à dignidade psíquica do indivíduo; c) Reiteração da conduta; d) Finalidade de exclusão. (NASCIMENTO, 2009, p. 41)

O assédio moral é uma forma de sofrimento no trabalho entre tantas outras existentes, e delimitar e distinguir com precisão o que se configura como assédio moral nem sempre se mostra uma tarefa fácil. Existem ainda, as falsas declarações de assédio moral e as queixas abusivas que apelam para o uso do termo, ou seja, nem tudo que é denominado como assédio moral de fato é. (HIRIGOYEN, 2002; MARTININGO FILHO, SIQUEIRA, 2008).

A dificuldade de identificar o assédio moral no contexto organizacional ocorre em função de causas múltiplas. Comumente ele é confundido com outros tipos de agressão. Podem, ainda, equivocadamente vigorar percepções de que se trata de um fato normal, principalmente frente à competitividade do mundo do trabalho. Seu início geralmente ocorre por meio de pequenos atos comumente considerados normais, insignificantes ou simples brincadeiras, quando analisados de forma isolada. Entretanto, essas atitudes muitas vezes marcadas pela repetição e unilateralidade, podem gerar um processo que desestrutura e fragiliza o outro. Neste sentido, Hirigoyen (2008) e Guedes (2008) destacam que, aparentemente inofensivo, o assédio moral costuma se propagar insidiosamente, como um fenômeno invisível e silencioso, que aniquila o outro sem alarde.

O assédio moral no contexto de trabalho, pode se configurar de várias maneiras e envolver distintos indivíduos. Fiorelli, Fiorelli e Malhadas (2007) descrevem a possibilidade da existência do assédio moral entre indivíduos de organizações diversas como, por exemplo, nas relações entre clientes e fornecedores.

Para autores como Hirigoyen (2002) Heloani (2003, 2004, 2011), Maciel (2007), Nascimento (2008), Freitas, Heloani e Barreto. (2008), o assédio moral envolve indivíduos que atuam na mesma organização. Nesta vertente, considerando a posição hierárquica ocupada pelos indivíduos envolvidos, o assédio moral pode ser classificado em dois tipos: o assédio vertical, nas suas formas ascendente e descendente; e o horizontal, que ocorre entre colegas ou pares. Também podem ser observadas combinações de assédios de distintas direções, gerando os tipos mistos.

O mais frequentemente detectado nas organizações é o assédio moral descendente, ou seja, um chefe assediando um subordinado. É neste clássico tipo de assédio que se observa mais explicitamente o abuso de poder e violência ao subjugar e submeter o subordinado a este domínio. Esta relação pode ser dual (assediador e assediado) ou envolver mais de dois indivíduos representados por agressores ou assediadores sobre um indivíduo; ou um agressor assediando mais de um indivíduo; ou mesmo, envolvendo agressores e assediados múltiplos. Nota-se que, em alguns casos, o agressor pode "conquistar" adeptos no que antes era considerada uma relação dual. Ressalta-se que o fenômeno do assédio moral implica, necessariamente, em uma diretividade predeterminada, mesmo quando engloba um maior número de assediados.

Neste artigo, compreende-se o assédio moral no trabalho como um problema relacionado a diversos fatores, tanto de cunho individual, relacional, organizacional e também macroeconômico. Entre as características que perpassam as relações de assédio moral no trabalho, destacam-se sua relação com os jogos de poder e mecanismos disciplinadores, a perversão moral do agressor e também do sistema social, a existência de intencionalidade da violência que ocorre por meio de humilhações, constrangimentos e ameaças muitas vezes veladas, localizadas em um espaço temporal marcado pela constância, frequência predeterminada e intensidade com que ocorrem.

Cabe ressaltar que se há divergência quando a conceituação e delimitação do assédio moral, o mesmo não ocorre ao analisar os resultados que gera. Pode-se dizer que há consenso entre os vários autores aqui citados sobre os prejuízos que o assédio moral provoca. "As consequências do assédio moral para a saúde da trabalhadora/do trabalhador são devastadoras. O assédio moral tem sido considerado como um dos mais importantes estressores nas organizações contemporâneas." (SOARES, OLIVEIRA, 2012, p. 197).

Para Glina e Soboll (2012) o assédio moral é considerado um potencial gerador de danos físicos e psicológicos nos assediados. Portanto, mostrase como um sofrimento para a vítima com sérias 
consequências, na medida em que atinge sua saúde física e emocional. Fragiliza e abala sua autoestima, aumenta os índices de estresse, provocam surgimento de doenças psicossomáticas tais como cefaleias, gastrites, úlceras, quadros de depressão e casos extremos como suicídios. As consequências para este indivíduo não se restringem ao seu contexto de trabalho, mas se estendem à vida familiar e seus relacionamentos sociais.

\section{O assédio moral e a organização de trabalho}

Práticas que causam humilhação e constrangimentos ao trabalhador não são características apenas da atual sociedade. Todavia, o modo de produção vigente, também conhecido como sistema capitalista, impregnado de valores como competitividade, individualismo e utilitarismo, e ao mesmo tempo carente de valores humanísticos, solidários e éticos, cria condições férteis para o surgimento do assédio moral.

Constata-se que a forma de organização do trabalho vem se alterando ao longo dos tempos (ANTUNES, 2000, 2005). Entretanto, no nosso país, foi a partir da década de 1990 que se observou uma intensificação das mudanças, seja em seu ritmo e dinamismo, como também no surgimento de novos modelos de produção. A globalização e os avanços da tecnologia repercutem no processo produtivo, alterando e provocando elevação da produtividade, mas também, em contra partida, eliminando empregos e alterando os vínculos no contexto de trabalho.

Freitas, Heloani e Barreto (2008) também afirmam que as transformações ocorridas nessa década foram diversas e englobam questões econômicas, políticas, sociais, culturais e tecnológicas. No cerne destas mudanças, nota-se uma valorização dos aspectos econômicos em detrimento de valores coletivos da sociedade. A ampliação e valorização do papel das organizações no contexto social contribuíram para gerar certa crise de identidade, seja pela insignificância dos indivíduos neste processo ou na desestruturação do coletivo. Para esses autores, a violência tem sua origem no enfraquecimento dos valores coletivos e exacerbação da competitividade e individualismo vigentes.

Ressaltam ainda a crescente desregulamentação dos direitos do trabalho, que estão sofrendo restrições em quase todas as partes do mundo, onde há produção industrial e de serviços. Neste contexto, pode-se dizer que, o emprego estável, com perspectiva de permanência e construção de uma longa carreira na mesma organização, vem desaparecendo ao longo do tempo. Os vínculos da organização com os indivíduos e vice-versa, tendem a ser estabelecidos em novas bases, sejam por intermédio de terceirizações, trabalhos temporários, parceiras, prestações de serviços, ou outras formas. Como consequências deste fenômeno, percebem-se o aumento da fragmentação no interior da classe trabalhadora, levando a uma precarização das relações de trabalho.

A tecnologia, muitas vezes desenvolvida para alavancar a produção e facilitar o trabalho, tende a cumprir o seu primeiro papel, mas ao romper com o paradigma tradicional de tempo e espaço, ampliou os períodos e os locais de trabalho, que antes eram precisamente delimitados, tornando tênue a divisão entre trabalho, família e lazer. Desta forma, o sistema produtivo leva à incorporação de uma carga horária adicional de trabalho ao indivíduo, que muitas vezes extrapola as conquistas das regulamentações legais sobre a jornada de trabalho, além de aprimorar (tornar mais eficientes e sutis) os mecanismos de controle organizacional.

Nesta mesma linha de abordagem, Heloani (2004, 2011) ressalta que o assédio moral está enraizado no nosso sistema macroeconômico, onde impera a racionalidade instrumental, submetendo uns indivíduos ao controle de outros, como uma forma disciplinar. Este autor questiona se não seria a própria hiper competitividade presente no contexto atual, uma forma de violência, pois atropela a ética e justifica os meios utilizados para se atingir um determinado objetivo. Esse autor afirma também, que a ideologia neoliberal extrai e minimiza os benefícios e direitos conquistados dos trabalhadores, modificando a relação capital e trabalho. Além disso, sustenta que o assédio moral é oriundo da lógica macroeconômica, na qual:

a violência torna-se uma resposta a um sistema desumano e não pode ser considerada como sendo um mero mecanismo individual. Em outras palavras, nesse processo, a violência passa a ser a perversão da perversão, ou seja, uma armadilha motivada pela crueldade do sistema (HELOANI, 2004, p.3). 
Seguindo este raciocínio, Sina (2007) e Glina e Soboll (2012) também associam o processo de globalização e a flexibilização das relações de trabalho, aos problemas de violência no trabalho.

O assédio moral no trabalho é fruto de um momento histórico e de um contexto social e econômico definidores da forma de organização do trabalho e do desenho das relações humanas neste contexto. Em última instância, trata-se de uma questão ética e de respeito à dignidade humana. (GLINA, SOBOLL, 2012, p. 279)

Inseridos no contexto macroeconômico, há ambientes corporativos que por si só podem ser considerados nocivos à saúde e fazem com que o local de trabalho seja um martírio. Ressaltado por Tavares (2004) e Vieira (2008) o trabalho além de ocupar grande parte da vida dos indivíduos, é importante na construção de sua identidade, afeta sua autoestima, socialização e adaptação na sociedade.

Ainda neste sentido, Peli e Teixeira (2006) destacam a importância do trabalho, pois é neste local que se permanece a maior parte do tempo. Além disto, o trabalho é fonte de sustento e representa o depositário de expectativas, aspirações e busca de realizações dos indivíduos. Assim, os conflitos e dificuldades vivenciados neste contexto invadem outros campos da vida do indivíduo, fazendo parte de sua história e interferindo sobre sua qualidade de vida em geral. Há interseção entre os aspectos da vida pessoal e profissional, portanto, um sofrimento gerado no trabalho estende-se a demais esferas da vida de uma pessoa.

Heloani $(2004,2005)$ e Sina (2007) ressaltam o fato de que modelos de gestão autoritários característicos do período industrial clássico, hoje são vistos como anacrônicos. Todavia, ainda há ambientes organizacionais que valorizam a agressividade, o estilo autoritário das chefias, e alguns profissionais ainda se orgulham deste tipo de comportamento. Na busca de maior produtividade e competitividade, certos modelos de gestão valorizam estilos mais agressivos ou, até mesmo, fomentam o aumento nos índices de conflito para estimular a concorrência interna e externa. Entretanto, este tipo de gestão nem sempre se mostra eficaz e pode ser prejudicial, tanto para a empresa quanto para os funcionários, pois descartam colaboração e fragmentam equipes.
Também evidenciando as implicações desse tema no âmbito das organizações, Hirigoyen (2008, p.93) considera o assédio moral como um comportamento de abuso de poder (mais perceptível no tipo descendente, chefe assediando subordinados) que encontra respaldo em alguns ambientes empresariais. "Se a empresa é assim condescendente, a perversão gera a emulação entre indivíduos, que não são propriamente perversos, mas perdem suas referências e se deixam persuadir". Desta maneira, a questão do assédio moral torna-se banal, os indivíduos habituam-se a fatos deste tipo, pois para algumas empresas os fins justificam os meios, e instaura-se aí um estímulo a perpetuação de métodos perversos.

Hirigoyen (2002) prossegue analisando as regras de gestão, e ressalta que em algumas organizações pode ser constatada a presença de toxidade e perversidade nas suas relações internas. Essa situação ocorre, por exemplo, quando a hierarquia impõe metas intangíveis ou difíceis de serem alcançadas pelo grupo, e este tende a excluir os indivíduos menos produtivos. Cabe destacar que há situações da ambiência organizacional que favorecem o surgimento e permanência do assédio moral, tais como o acentuado índices de estresse, sobrecarga de trabalho, desaparecimento dos diálogos, falta de reconhecimento, permissividades, processos de comunicações ambíguos e a pouca clareza de limites, que fomentam comportamentos de violência, seja na impunidade daqueles que a praticam, como também no "convite" à conivência e passividade dos demais. Neste sentido, Freitas, Heloani e Barreto (2008, p. 39 e 40), destacam situações abusivas e degradantes consideradas normais em algumas organizações:

Rituais degradantes e ofensivos podem ser desenvolvidos e justificados para punir os profissionais que não atingem suas metas ou aqueles que têm a sua admissão ou permanência protegida legalmente (portadores de necessidades especiais, gestantes, acidentados em reinserção, estrangeiros, etc.). A criatividade mórbida e repetitiva sugere que essas organizações são sádicas, estimulando rituais que podem assumir diferentes formas: o funcionário "pagar" com exercícios de flexões de braço enquanto é xingado pelos colegas, ser obrigado a vestir-se e a maquiar-se de mulher, usar camisetas com dizeres ofensivos, fazer coreografias vexatórias e com gestos obscenos, aceitar ser chicoteado ou ganhar chicotes de presente do 
chefe, ser açoitado enquanto escuta mensagens ofensivas e cruéis, etc.

Considerando o ambiente macrossocial e organizacional como fomentadores da violência moral no trabalho, Freitas, Heloani e Barreto (2008) receiam a isenção de responsabilidades pessoais. Tal qual Hirigoyen (2002), esses autores acreditam que é preciso identificar e punir indivíduos e respectivas empresas. Entretanto, uma pergunta pode ser efetuada nesta situação: o que faz com que um indivíduo permaneça em tal condição penosa? Em períodos de precariedade e escassez de trabalhos com vínculo empregatício, aqueles que continuam empregados sentem-se "privilegiados" e procuram resistir, o quanto podem, para manter-se no emprego.

Sina (2007) e Freitas, Heloani e Barreto (2008) ressaltam que as pessoas se submetem a situações degradantes e tratamentos desrespeitosos por medo de perder o emprego. Além disto, Hirigoyen (2008) afirma que muitas vezes é difícil para o assediado se conscientizar que está sofrendo assédio moral, pois o processo da perversão utiliza métodos que confunde, impede e até imobiliza as vítimas de reagir.

Assim, a existência de assédio moral no trabalho está intimamente arraigada ao ambiente da organização e, portanto, deve ser considerada como um problema e uma questão do âmbito e da responsabilidade organizacional. Ao surgir naquele contexto, não significa que resultou da vontade dos dirigentes, mas, no mínimo, apontam comportamentos inadequados, negligentes ou omissos destes. (HIRIGOYEN, 2002; FREITAS, HELOANI, BARRETO, 2008; MARTINIGO FILHO, SIQUEIRA, 2008).

\section{A área de Recursos Humanos e o problema do assédio moral: Adequações e inadequações}

Analisando a posição e o papel da área de Recursos Humanos (RH), observa-se que essa se encontra em uma difícil posição, desafiada constantemente no sentido de mediar interesses antagônicos: de um lado os empresários e do outro os empregados.

Tendo sua origem ligada à administração científica, à racionalização de processos, à busca de maior produtividade e aos métodos de controle e otimização da mão de obra, a área de RH surgiu como mais um entre outros componentes da estrutura organizacional. Ao longo da sua trajetória, a área de Recursos Humanos, alterou e ampliou gradativamente sua visão e sua forma de atuar.

Desde os anos 1990, na considerada "era da informação", constatam-se reflexões sobre o papel da área de RH. As consequências das mudanças no ambiente empresarial também impactaram a atuação da área de $\mathrm{RH}$, que precisou mudar e se adequar as exigências do novo contexto. Autores como Ulrich (2002), Gil (2001), Ribeiro (2005), Mascarenhas (2008), entre outros, destacam que a globalização, os avanços tecnológicos, os novos vínculos de trabalho, as exigências de novas competências, a busca pela competitividade e a necessidade de contribuir efetivamente para o sucesso da organização, constituem novos desafios impostos aos profissionais da área de recursos humanos, modificando seus papéis, funções e responsabilidades.

Ulrich (2002) afirma que é necessário promover mudanças na forma de estruturação da área de RH, para que esta seja capaz de acompanhar a competitividade e novas demandas das empresas. Ressalta também, a importância dessa área incorporar simultaneamente, quatro novos papéis e funções: estratégico, administrador de processos, agente de mudanças e também administrador da contribuição dos funcionários. Assim, para atuar estrategicamente, ela deve se posicionar de forma alinhada com os negócios e a estratégia organizacional, para desenvolver melhor seu trabalho e gerar contribuições organizacionais. Quanto ao papel de administrador de processos, pode-se dizer que deve atuar aprimorando e desenvolvendo processos eficientes e eficazes para contratar, reter, capacitar, avaliar, monitorar e gerir os funcionários. Como agente de mudanças, os profissionais de recursos humanos devem ser os catalizadores culturais, ajudando a identificar, programar e atuar na implementação das transformações necessárias. Para descrever o quarto papel, o autor utiliza a metáfora "defensores dos funcionários", referindo-se justamente a função de aproximação e envolvimento com os funcionários, identificando, compreendendo e ajudando a resolver seus problemas e preocupações, além de receber suas sugestões e contribuições, pois entende que o "capital humano" é fundamental para o sucesso organizacional. 
Mascarenhas (2008) também defende a necessidade de mudanças na área de Recursos Humanos, tal qual Ulrich (2002) propôs, a partir de uma reestruturação e incorporação de múltiplos papéis.

Ao observar a importância dos profissionais de RH, Ribeiro (2005) destaca que além a formação adequada e conhecimentos técnicos, estes precisam ter competências comportamentais que possibilitem uma boa atuação na área. Para ele:

É essencial que o profissional tenha não só formação humanística, mas, também principalmente, que seja dotado de uma empatia profunda para estabelecer relações proveitosas, seja com os executivos da empresa, seja com os trabalhadores de chão de fábrica. (RIBEIRO 2005, p.3)

Entre outras questões, ressalta como parte da função de RH assegurar um bom ambiente de trabalho e de forma alinhada aos negócios da organização, atuar como consultores internos, orientando os líderes na gestão das pessoas.

É importante destacar que há uma forte relação entre as políticas de $\mathrm{RH}$ e os valores das principais lideranças da organização. Pode-se dizer que, a área de RH reflete a cultura da organização, servindo-se, inclusive, de suas práticas para reforçar e manter os valores organizacionais vigentes. Assim, a existência de assédio moral, principalmente quando ocorre com frequência em uma dada organização, deve ser compreendido como desvirtuamento de valores, que precisam ser alterados e revertidos por intermédio de uma intervenção e atuação conjunta dos respectivos dirigentes e dos profissionais do RH. Portanto, entende-se aqui, que se trata de um problema diretamente relacionado às funções e responsabilidades da área de RH.

Com relação a este problema, os autores Peli e Teixeira (2006, p.199) afirmam que:

Todo trabalhador da Empresa que sofra ou conheça dos ilícitos definidos como Assédio Moral e/ou Assédio Sexual, conforme definido pela doutrina jurídica e/ou por este regulamento, tem o direito e o dever de denunciá-los, por escrito, aos órgãos indicados. Na ausência destes, procure a área de Recursos Humanos, a qual estará obrigada a tratar $\mathrm{o}$ assunto com a confidencialidade exigida, encaminhando a solução do problema.
A área de RH tem, portanto, o dever e a responsabilidade de investigar com autonomia e imparcialidade as denúncias de assédio moral, respeitando aspectos de confidencialidade e comunicando os resultados àqueles de direito, cabendo sugerir medidas, tanto de caráter preventivo, quanto acautelatórias, de forma a preservar um ambiente de trabalho adequado até a conclusão da investigação (PELI; TEIXEIRA, 2006).

Também Glina e Soboll (2012, p.12) ressaltam que a área de RH deveria atuar de forma interventiva e mediadora para minimizar questões de assédio moral. A atuação como ouvidoria e como arbitragem mostra-se pertinente e efetiva no início do processo, antes do assédio se configurar como um problema crônico. As intervenções no âmbito organizacional devem abordar mudanças nas estruturas na organização, desde alterações nas políticas, valores, estilos predominantes das lideranças, como também na organização do trabalho e nas práticas de recursos humanos.

Entretanto, não raro, a área de Recursos $\mathrm{Hu}$ manos ainda tende a ignorar questões referentes a situações de assédio moral no contexto de trabalho. A este respeito, Heloani (2005) ressalta que, diante do assédio moral, é comum que a vítima sinta medo de denunciar e sofrer represálias, optando por permanecer em silêncio. Contudo, algumas vítimas conseguem investir esforços na procura de apoio e solução. Dados de uma pesquisa realizada por Hirigoyen (2002, p. 289) na França, revelaram que, quando os funcionários precisaram e buscaram ajuda para lidar com este problema, não encontraram o devido auxílio no âmbito da organização. Os resultados da pesquisa mostraram, ainda, que apenas 19\% das vítimas buscaram a área de $\mathrm{RH}$, sendo que somente $1 \%$ deles obteve ajuda dos profissionais da área.

Para Hirigoyen (2002), a área de RH quando ciente do problema de assédio reage com comportamentos de negação, banalização ou perplexidade. Freitas (2007) critica a atuação e postura do RH, quando este adota a "dolosa política de avestruz", preocupada com a própria sobrevivência, tende a se omitir. Este fato retrata uma situação preocupante que abala a imagem e a credibilidade desta área, além de evidenciar o despreparo de seus profissionais para lidar com questões de assédio moral. Pois, ao contrário, o RH deveria ser uma área com melhor condição 
para lidar com estes problemas, e seus profissionais deveriam possuir neutralidade e competência para intervir adequadamente, visto que representam o elo entre dirigentes e funcionários.

Além deste despreparo e ausência de intervenções adequadas, existem outros agravantes que comprometem o desempenho da gestão do RH. Dessa forma, não é raro encontrar práticas de constrangimentos nos processos que envolvem diretamente a própria área de RH. São situações incoerentes e mesmo paradoxais, quando se entende que esta deveria ser uma área composta por profissionais com uma visão mais humanista e que estão preocupados com a preservação de um bom ambiente e um clima de trabalho respeitoso e ético.

Observa-se, ainda, que a área de RH atua de forma contingencial e seus processos são diretamente impactados pelo movimento e contexto do mercado de trabalho. Pode-se dizer que os processos de captação e seleção de pessoas, estabelecem uma relação espelhada como as relações de mercado. Por exemplo, quando existem muitos profissionais disponíveis e interessados em conseguir um trabalho, em relação a uma menor oferta de vagas, percebe-se maior rigor nos processos seletivos. Esta situação revela-se favorável às organizações, possibilitando escolher entre os candidatos interessados, aqueles mais qualificados e com melhores condições de ter um bom desempenho e adaptação na empresa. Este é um procedimento típico da seleção de pessoal que envolve diretamente a área de RH. Todavia, nota-se que alguns processos seletivos têm exagerado na definição das exigências e requisitos dos candidatos, chegando a pecar pelo excesso. Muitas vezes, as exigências aos candidatos excedem as características das funções previstas, o que geralmente causa frustrações futuras, comprometendo, inclusive, a eficácia de tal seleção. Além disto, e o mais grave, é o fato de que algumas empresas extrapolam o rigor e exigências e ingressam no campo do constrangimento, ao impor aos candidatos atividades desnecessárias, inadequadas ou mesmo desrespeitosas.

É comum ocorrer em processos seletivos a utilização de técnicas de ética questionável, que expõem aspectos da vida íntima dos candidatos, por meio de perguntas invasivas ou de cunho discriminatório. Nas situações coletivas, estimulam os candidatos a se comportarem como "gladiadores" para permane- cerem no processo, incentivando a agressividade e desrespeito, e, tentando justificar o injustificável, alguns selecionadores alegam que este procedimento é necessário para verificar como os candidatos reagem em situações de maior pressão ou estresse.

Os processos seletivos já vêm sendo alvo de críticas de candidatos que vivenciaram experiências desagradáveis e infelizes, e que muitas vezes ficam aguardando em vão pelo prometido retorno sobre o processo do qual participaram. Além da seleção de pessoal, outros processos próprios da função de RH nas organizações, mostram-se repletos de inadequações. Práticas de integração de novatos, modismos nos campos de treinamentos comportamentais, alguns programas de desenvolvimento que incluem dinâmicas de grupos impostas e inoportunas, já foram objeto de críticas por parte de vários autores, como Hirigoyen (2002; 2008); Heloani (2004); Sina (2007); Freitas et. al (2008); e Guedes (2008). Outras práticas de gestão de RH que também foram criticadas por parte destes autores, são a ausência de gestão de funcionários terceirizados, avaliações de desempenho mal conduzidas e processos demissionais desrespeitosos que constituem práticas investidas de legitimidade e justificadas através de uma pseudo cientificidade.

Também é preciso destacar os exageros que alguns programas de trainees cometem, seja na seleção dos candidatos, ou na integração e socialização dos aprovados e contratados. Justificados pela intensa concorrência e competição dos jovens com desejo e esperança de ingressar em uma grande corporação, observam-se abusos e exposições exacerbadas e desnecessárias. Estes jovens profissionais, ainda com pouca maturidade e experiência, ficam vulneráveis a este tipo de violência. Alguns se sentem incomodados, constrangidos, envergonhados, enquanto outros procuram incorporar aquelas situações como normais, já demonstrando indícios do mimetismo e atuação futura de um profissional que está sendo iniciado na "escola" organizacional para a qual tanto se esforçou para conseguir ingressar. Sobre estes programas de trainees, Freitas et. al (2009, p. 41), afirmam que se trata de "um verdadeiro crime contra o futuro perpetrado por organizações em que se cultivam a indiferença, a insensibilidade e o desrespeito ao outro". 
Ainda sobre essas práticas, Guedes (2008, p.96) enfatiza que:

[...] da simples e conhecida violação da intimidade, colhida nos processos de seleção, avançamos para uma nova face do abuso moral. Grandes empresas multinacionais vêm, de modo repetido e deliberado, fazendo uso de práticas perversas e submetendo jovens candidatos á estágios e trainees, com pseudojustificação de estarem estimulando o atual ambiente de stress, no qual todos devem acostumar-se a dar respostas rápidas e não entrar em pânico. Perguntas imorais, insinuações sexuais e ofensivas à dignidade individual são utilizadas sem maiores pudores em nome de um empirismo perverso que pretende verificar a capacidade de o candidato manter sangue frio e a passividade, diante do estupro moral provocado por esses avaliadores.

Ao analisar esses aspectos, Sina (2007) destaca as inadequações de alguns processos de avaliação de desempenho, usada por alguns gestores como instrumento de controle e finalidade exclusiva para punir uns e beneficiar outros, o que gera insatisfação e receio nos funcionários. Nota-se que, aqui a crítica não se refere aos processos de avaliação de desempenho, percebidos como instrumentos de oportunidade de aprimoramento da performance tanto dos indivíduos quanto das organizações. Ressalta-se que, a crítica procede quando se analisa o uso inadequado destes, vistos e utilizados como instrumentos de poder para manipular e justificar promoções, demissões e outras decisões gerenciais, a partir de critérios nem sempre claros e de cunho subjetivo. Nestes casos, há portanto, uma inversão de valores, e o que deveria ser utilizado para melhorar os processos - sair-se bem nas avaliações de desempenho - de meio, transforma-se em um fim.

Da mesma forma, a postura crítica que se faz presente neste trabalho, não é relativa à área de Recursos Humanos e seus processos em si, que são considerados importantes e necessários ao contexto organizacional, mas sim, aos equívocos que se comentem nestas práticas, por meio ou omissão dos seus profissionais.

\section{Assédio Moral, delimitações e diferenciações de outras práticas}

$\mathrm{Na}$ perspectiva jurídica, Vieira e Scalco (2010) afirmam que uma agressão pontual não se configura como assédio moral. Nesta mesma linha de raciocínio, Hirigoyen (2002) complementa e afirma que conflitos, desentendimentos e erros de gestão específicos, quando inexiste a má intenção, geram mal estar e sofrimento, mas não podem ser considerados como assédio moral. Este último causa consequências destruidoras e de aniquilamento do outro. Quando as condições de trabalho em geral mostram-se inadequadas, tais como sobrecarga de atividades, estresse acentuado, dificuldade de relacionamentos interpessoais, rígidas hierarquias, mas não há intencionalidade e diretividade, embora prejudique a saúde dos trabalhadores, mas por si só, não se configuram como assédio moral. Entretanto, não raro, o que antes eram questões isoladas e especificas, com a frequência e constância, podem se tornar habituais e adquirir contornos típicos de assédio moral. Nota-se, assim, um limiar tênue e mutável entre o que é ou não assédio moral.

Já para Nascimento (2009) existem nas organizações várias práticas direcionadas ao trabalhador que podem ser consideradas espécies distintas de comportamentos que causam constrangimentos no trabalho, tais como assédio moral, sexual, lesão à imagem ou lesão à intimidade ou à honra. Apesar das semelhanças (causar danos e incentivar a demissão), configuram-se como práticas diversas, cada uma delas implicando em determinados padrões comportamentais, por parte daquele que infringe o ato constrangedor no contexto de trabalho.

Outros autores como Peli e Teixeira (2006) registram a diferença entre assédio moral e assédio sexual, este último já contando com previsão legal no ordenamento jurídico brasileiro (Art. 216 - A do Código Penal Brasileiro). Constata-se também, uma diferença entre o que se configura como assédio e ações de discriminação. No assédio moral, independentemente das características pessoais da vítima, o objetivo é a sua humilhação. "Já a discriminação se dá pela retirada ou restrição a um direito, como por exemplo, na questão racial, na qual por vezes tenta-se impedir o direito de ir e vir ou, ainda, em relação às pessoas portadoras de necessidades especiais" (PELI;TEIXEIRA, 2006, p.31).

Esses autores afirmam que, no Brasil, foram observados avanços na legislação da administração pública de alguns estados e municípios, mas ainda não há uma legislação nacional que defina e tipifique 
o assédio moral. Entretanto, entendem o assédio moral como um tipo de dano moral e, de forma subsidiária ou por analogia, a legislação vigente no campo trabalhista, cível ou penal, pode e deve ser aplicada.

Para Freitas et. al (2008, p. 90), o "assédio moral contém dano, ou melhor, é uma constelação de danos morais, de microtraumas psíquicos" ou seja, todo assédio moral contem dano ou um conjunto de danos morais embutidos em si mesmo, mas o inverso nem sempre é verdadeiro. Pode-se dizer que o assédio moral é um tipo de dano moral. Nascimento (2009, p.138 e 139) esclarece as distinções sobre os danos na esfera cível:

[...] o dano moral configura-se pela violação do direito geral de personalidade, atingindo interesses sem expressão econômica. $\mathrm{O}$ dano material, também chamado pela doutrina de dano patrimonial, refere-se ao dano que repercute sobre o patrimônio da vítima, suscetível de aferição econômica. Quanto ao dano estético ou da imagem, importante ressaltar que parcela da doutrina os classifica entre os danos morais. Outra parcela entre os danos materiais e há quem os considere um terceiro gênero (tertium genus)

Essa autora ressalta que situações que lesam o trabalhador podem gerar distintos danos. A jurisprudência admite acumulação de indenizações, de danos morais e materiais, pois suas causas são distintas. $\mathrm{O}$ assédio moral no trabalho é uma conduta ilícita e que pode gerar demissão, por justa causa, ao assediador. Para a organização, por culpa ou dolo, pode acarretar pagamento como ressarcimento de danos morais, mediante reclamação da vítima na justiça do trabalho.

Normalmente, os abusos e constrangimentos impetrados aos indivíduos durante os processos seletivos, onde ainda inexiste um contrato de trabalho, em período de curta exposição, portanto, na ausência de repetição prolongada, enquadram-se na classificação jurídica como dano moral. Nas fases pré-contratuais podem acontecer discriminações e preconceitos que ferem dispositivos legais e são passíveis de enquadramento jurídico e indenizações.

Freitas (2007) afirma ainda que, os prejuízos decorrentes de assédio moral no trabalho são complexos e múltiplos acarretando uma elevada conta paga por instâncias distintas, que se sobrepõem: o indivíduo, a organização e a sociedade. Para o indi- víduo, as consequências, já descritas no início deste trabalho, atingem sua saúde e vida psíquica, profissional, familiar, afetiva e social. Para a organização, constata-se a elevação dos índices de absenteísmo e turnover, queda da produtividade, clima desagradável e dano à imagem organizacional, além de gerar custos indenizatórios. Para esta autora, em um contexto mais amplo, mas muitas vezes ignorado, toda a sociedade paga a elevada conta do assédio moral, seja nas aposentadorias precoces, nos acidentes de trabalho, no aumento das despesas médicas e previdenciárias, nas destruições familiares e até nos índices de suicídios.

\section{Conclusões}

Diante da multiplicidade de suas causas, pode-se concluir que não existem soluções simples para o assédio moral no trabalho. Trata-se de um problema grave que requer soluções múltiplas: de ações preventivas a corretivas. Também requer intervenções e providências dos distintos níveis de responsabilidades envolvidos, seja individual, organizacional e social.

Perceber a existência de assédio moral no contexto de trabalho não se mostra tarefa fácil, pois conforme Hirigoyen (2008, p. 9) a sociedade tende a se tornar cega a este tipo de violência, e a "pretexto da tolerância, nos tornamos complacentes" com tais práticas. É preciso, pois, resgatar valores éticos e estabelecer relacionamentos interpessoais baseados no respeito pelo ser humano.

Refletir sobre o assédio moral implica em fazer uma revisão e alteração de valores e posturas individuais, organizacionais e, até mesmo, da sociedade em geral. No contexto da sociedade, ainda é preciso prosseguir com os avanços na legislação, punindo os responsáveis e coibindo ações de assédio moral futuras. Entretanto, a solução para o problema do assédio moral no ambiente de trabalho não se relaciona somente com avanços e aplicações de aspectos legais. É necessário investir na conscientização e educação dos trabalhadores, além de promover a mobilização dos sindicatos e trazer os conselhos profissionais de classe para este debate, seja na fiscalização de tais condutas constrangedoras e inadequadas, como também conscientizando seus 
profissionais sobre o papel e responsabilidade das ações nos ambientes organizacionais.

É importante destacar negativamente a utilização de práticas de constrangimentos, percebidas em alguns processos de trabalho da área de Recursos Humanos nas organizações. Elas representam um contra senso, um paradoxo, na medida em que o discurso atual nas organizações é de "máxima valorização do Capital Humano".

Como campo multidisciplinar, a área de RH comporta profissionais de diversas formações. Entre eles, destacam-se as presenças de Administradores e Psicólogos. Esses últimos, por deterem domínio no uso dos testes psicológicos, mostram-se como presença predominante nos processos seletivos e são alvos frequentes de críticas, infelizmente, muitas vezes pertinentes. De formação eminentemente humanística, é esperado que estes profissionais fossem considerados como referências quanto à sensibilidade, habilidades interpessoais, empatia e respeito no trato com os indivíduos. É necessário, portanto, levar estas discussões para o campo acadêmico, no que tange à formação destes profissionais. Urge incluir ou aprofundar nas pautas curriculares das disciplinas relacionadas à gestão de Recursos Humanos, Psicologia e Trabalho, Comportamento Organizacional e demais disciplinas correlatas, a responsabilidade ética na conduta dos seus respectivos processos e, especificamente, refletir sobre questões relativas ao assédio moral no contexto de trabalho.

Sabe-se que a área de Recursos Humanos reflete a cultura organizacional e, por intermédio de suas práticas, pode agir para manter ou modificar os valores compartilhados coletivamente. Contudo, esta área ainda precisa se conscientizar mais do seu papel e importância, além permanecer atenta a existência ou indícios de ambiência propícia para proliferação de ações de assédio moral.

Além disto, cabe aos profissionais de Recursos Humanos conquistarem maiores espaços para atuação estratégica, o que ainda se mostra longe da realidade na maioria das empresas brasileiras. A atuação predominantemente operacional e reativa dificulta intervenções em práticas de constrangimentos ou assédio moral. Entretanto, isto não pode ser utilizado como desculpa ou justificativa para a omissão, negligência ou ainda mais grave, a conivência.
Os profissionais que atuam na área de Recursos Humanos podem e devem agir para impedir a existência ou proliferação de práticas de assédio moral no contexto organizacional. Para tal, devem pautar sua postura, conduta e ações profissionais como modelo ético a nortear os demais profissionais da organização. É preciso conquistar maior credibilidade para receber queixas e denúncias, dando a estas os encaminhamentos adequados. Tal como Ulrich (2002) preconizou, ao assumir seus múltiplos papéis, as contribuições da área de Recursos Humanos se ampliam.

Como área consultiva, a referida área deve orientar os gestores e dirigentes sobre as consequências, responsabilidades e prejuízos que o assédio moral pode causar. Deve também, intervir, em situações de conflitos e esclarecer a importância de um bom ambiente de trabalho. Realizar processos de desenvolvimento gerencial corroborando na preparação de lideranças eficazes, inclusive, aptas a intervir diante de indícios de assédio moral.

A área de RH deve também, trabalhar no sentido de buscar identificar causas de absenteísmos, turnover, além do monitoramento do clima organizacional, destacando um olhar atento à existência de indícios ou práticas de assédio moral. Sugere-se também, a elaboração de códigos de ética e principalmente políticas de Recursos Humanos que estimulem respeito, meritocracia e favoreçam uma ambiência de trabalho adequada. Quando necessário, as práticas de $\mathrm{RH}$ podem favorecer modificações na cultura organizacional, como agentes de sensibilização de mudanças, ajudando a romper hábitos e comportamentos inadequados de constrangimentos.

Finalmente, pode-se concluir que o assédio moral representa uma degradação dos valores humanos e deve ser banido do contexto social e organizacional. Para tal, torna-se necessário que se envide esforços integrados, com destaque para as ações dos dirigentes e dos profissionais de Recursos Humanos, considerando seu papel e responsabilidade destes frente a este problema. Assim, é preciso sair de uma postura omissa e de indiferença e posicionar-se contra a incidência perversa do assédio moral no contexto de trabalho. 


\section{Referências:}

ANTUNES, Ricardo. Os sentidos do trabalho: ensaio sobre a afirmação e a negação de trabalho. 2 ed. São Paulo: Boitempo, 2000.

Adeus ao Trabalho?: ensaio sobre as metamorfoses e a centralidade do mundo do trabalho. $10^{\mathrm{a}} \mathrm{ed}$. São Paulo: Cortez; Campinas, SP: Editora da Universidade Estadual de Campinas, 2005

Barreto, M. M. S. (2000). Uma jornada de humilhações. Dissertação de Mestrado em Psicologia Social. PUC, São Paulo.

(2005). Assédio moral: a violência sutil. Análise epidemiológica e psicossocial no trabalho no Brasil. Tese de Doutorado, não publicada, em Psicologia Social. Pontifícia Universidade Católica de São Paulo, São Paulo.

DI MARTINO, V.; HOEL, H.; COOPER, C. Preventing violence and harassment in the workplace. Ireland: European Foundation for the Improvement of Living and Working Conditions, 2003.

FIORELLI, J. O. ; FIORELLI, M. S; MALHADAS Junior, M. J. Assédio Moral: uma visão multidisciplinar. São Paulo: LTr, 2007

FREITAS, M. E. Quem paga a cota do assédio moral? In: RAE-Eletrônica, V6, N 1, art. 5 , jan/um, 2007 . www.rae. com.br/eletronic

FREITAS, M. E; HELOANI, J. R. ; BARRETO, M. Assédio moral no trabalho. São Paulo: Cengage, 2008

GIL, A. C. Gestão de pessoas: enfoque nos papéis profissionais. São Paulo: Atlas, 2001.

GLINA, D. M R; SOBOLL, L A. Intervenções em assédio moral no trabalho: uma revisão da literatura. Rev. bras. saúde ocup., São Paulo, v. 37, n. 126, Dec. 2012 .

GUEDES, Márcia Novaes. Terror psicológico no trabalho. $3^{\mathrm{a}}$ Ed. São Paulo: LTr, 2008

HELOANI, J. R. Violência Invisível . In: RAE Executiva, vol.2, n⿳3 3 , ago/ out, 2003

Assédio Moral - um ensaio sobre a expropriação da dignidade no trabalho. In: RAE-Eletrônica, v3, n 1, art. 10, Jan/jun, 2004.

A Dança da Garrafa: Assédio Moral nas Organizações. Rev. GV Executive 50 vol.10 nº 1 jan/ jun 2011

HIRIGOYEN, Marie - France. Assédio moral: a violência perversa no cotidiano. $10^{\mathrm{a}} \mathrm{Ed}$. Rio de Janeiro: Bertrand Brasil, 2008.

Mal estar no trabalho:

Redefinindo o assédio moral. Rio de Janeiro: Bertrand Brasil, 2002
MACIEL, R. H et al. Auto relato de situações constrangedoras no trabalho e assédio moral nos bancários: uma fotografia. In: Psicologia e Sociedade; 19(2):117 -128, 2007

MASCARENHAS, A. O. Gestão estratégica de Pessoas: evolução, teoria e crítica. São Paulo: Cengage, 2008

MARTININGO FILHO, A.; SIQUEIRA, M. V. S. Assédio Moral e Gestão de Pessoas: uma análise do assédio moral nas organizações e o papel da área de gestão de pessoas. RAM - Revista de Administração Mackenzie, v.9, n. 5, 2008, p. 11-34

NASCIMENTO, S. M. Assédio Moral. São Paulo: Saraiva, 2009

PELI, P.; TEIXEIRA, P. Assédio moral: uma resposta corporativa. São Paulo: Ícone, 2006

RIBEIRO, A. L. Gestão de pessoas. São Paulo: Saraiva, 2005

SINA, Amália. A outra face do poder. São Paulo: Saraiva, 2007

SOARES, A.; OLIVEIRA, A.J. O assédio moral no trabalho: uma breve introdução. Rev. bras. Saúde ocup., São Paulo, 37 (126): 195-202, 2012

SOARES, Angelo. As Origens do conceito de assédio moral no trabalho. Rev. bras. Saúde ocup., São Paulo, 37 (126): 284-286, 2012

TAVARES M, A clínica na confluência da história pessoal e profissional. In: CODO, Wanderley (org) O trabalho enlouquece?: Um encontro entre a clínica e o trabalho. Petrópolis, RJ: Vozes, 2004

ULRICH, David. Os campeões de recursos humanos: inovando para obter os melhores resultados. Tradução Cid Knipel. 6 reimpressão. São Paulo: Futura, 2002

VIEIRA, Carlos Eduardo Carrusca. Assédio do moral ao psicossocial. Desvendando os enigmas da organização do trabalho. Curitiba: Juruá, 2008

VIERA, T. R; SCALCO, M. Assédio Moral. A mulher como vítima. Revista Jurídica Consulex. Ano XIV, no 315 , fevereiro de 2010

Recebido: 20-07- 2014

Aceito: 20-07- 2015 